\title{
Influence of cross-sectional ratio of down comer to riser on the efficiency of liquid circulation in loop air lift bubble column
}

\author{
Tatsumi Yamamoto ${ }^{1, *}$, Hiroyuki Kawasaki ${ }^{1}$, and Hidetoshi Mori ${ }^{1}$ \\ ${ }^{1}$ Dep. Life Sciences and Bioengineering, Univ. Toyama, 3190 Gofuku, Toyama, 930-8555, Japan
}

\begin{abstract}
Loop type bubble columns have good performance of liquid circulation and mass transfer by airlift effect, where the liquid circulation time is an important measurable characteristic parameter. This parameter is affected by the column construction, the aspect ratio of the column, the cross-sectional area ratio of down comer to riser $(R)$, and the superficial gas velocity in the riser $\left(U_{\mathrm{GR}}\right)$. In this work, the mean gas holdup and the liquid circulation time $\left(T_{\mathrm{C}}\right)$ have been measured in four types of loop airlift type bubble column: concentric tube internal loop airlift type, rectangular internal loop airlift type, external loop airlift type, external loop airlift with separator. Air and tap water were used as gas and liquid phase, respectively. The results have demonstrated that the mean gas holdup in riser increases in proportion to $U_{\mathrm{GR}}$, and that it in downcomer changes according to the geometric parameters of each bubble column. $T_{\mathrm{C}}$ has been found to conform to an empirical equation which depends on $U_{\mathrm{GR}}$ and the length of draft tube or division plate in the region of $0.33<R<1$.
\end{abstract}

\section{Introduction}

Various styles of bubble column are used as gas-liquid two phase or gas-liquid-solid three phase reactor in the plants for energy supply and environment conservation. The loop type bubble column is particularly important because of good performance of liquid circulation and mass transfer by airlift effect $[1,2]$. In this type bubble column, the liquid circulation time and the gas holdup are the important and characteristic parameters [3, 4], including the column construction, the aspect ratio of the column, the cross-sectional area ratio of down comer to riser $(R)$ and the superficial gas velocity in the riser $\left(U_{\mathrm{GR}}\right)$ [5]. For a well-understandings of the behavior of the loop type bubble column, we have to collect the data on various styles of the loop type bubble column.

We have already presented the behavior of the mean gas holdups $\left(\varepsilon_{\mathrm{GR}}, \varepsilon_{\mathrm{GD}}\right)$ in riser and downcomer and $T_{\mathrm{C}}$ measured in rectangular internal loop airlift type bubble column in a previous congress [6]. In this paper, we report these behaviors observed in four types of loop airlift bubble column: concentric tube internal loop airlift type, rectangular internal loop airlift type, external loop airlift type, external loop airlift type with separator.

\footnotetext{
${ }^{*}$ Corresponding author: yamamoto@eng.u-toyama.ac.jp
} 


\section{Experimental}

Four types of airlift bubble column used in this work are illustrated in Figure 1. The details of rectangular internal-loop type were presented previously [6]. The dimensions of bubble column are tabulated in Table 1 . Air and tap water at $303 \mathrm{~K}$ were used as the gas and liquid phase, respectively. A perforated plate with many holes was used as a gas disperser. The non-aerated liquid level $\left(H_{\mathrm{D}}\right)$ was kept at $0.12 \mathrm{~m}$ from the upper end of the draft tube or the division plate. The mean gas holdups $\left(\varepsilon_{\mathrm{GR}}, \varepsilon_{\mathrm{GD}}\right)$ in riser and downcomer sections were calculated by measuring the liquid height with a static pressure manometer. A tracer technique was used to measure the liquid circulation time $\left(T_{\mathrm{C}}\right)$ with a conductance meter and $20 \mathrm{wt} \%$ sodium chloride aqueous solution.
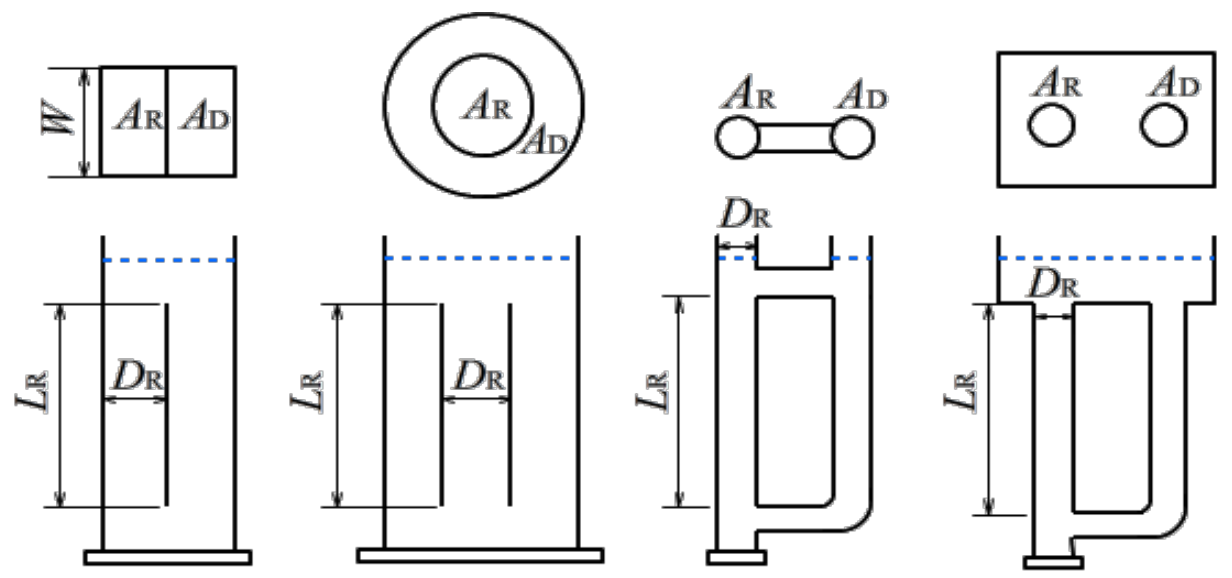

RIL

Rectangular Internal-loop

CIL Concentric-tube Internal-loop
EL

External-loop
ELS

External-loop with separator

Fig. 1. Four types of loop airlift bubble column employed.

Table 1. Dimensions of loop airlift bubble column employed.

\begin{tabular}{|c|c|c|c|c|}
\hline Column type & $\boldsymbol{R}\left(=\boldsymbol{A}_{\mathbf{R}} / \boldsymbol{A}_{\mathbf{D}}\right)[-]$ & $\boldsymbol{L}_{\mathbf{R}}[\mathbf{m}]$ & $\boldsymbol{D}_{\mathbf{R}}[\mathbf{m}]$ & $\boldsymbol{W}[\mathbf{m}]$ \\
\hline $\begin{array}{c}\text { Rectangular } \\
\text { Internal-loop (RIL) }\end{array}$ & $0.33-3.00$ & $0.77-2.50$ & $0.08-0.24$ & 0.12 \\
\hline $\begin{array}{c}\text { Concentric tube } \\
\text { Internal-loop (CIL) }\end{array}$ & $1.12-6.20$ & $0.50-4.06$ & $0.06-0.22$ & - \\
\hline External-loop (EL) & $0.44-3.06$ & $1.03-4.12$ & $0.02-0.15$ & - \\
\hline $\begin{array}{c}\text { External-loop } \\
\text { with Separator (ELS) }\end{array}$ & $0.38-14.06$ & $1.19-4.46$ & $0.04-0.15$ & - \\
\hline
\end{tabular}




\section{Results and Discussion}

\subsection{Bubble Distribution Pattern}

Shapes of bubble generated through the perforated plate were predominantly spherical. The bubbles rose with a constant velocity without colliding or coalescing one another inside the riser in low $U_{\mathrm{GR}}$ region. When $U_{\mathrm{GR}}$ was increased, some bubbles entrained into the main liquid flow from the riser to the downcomer. The amount of entrained bubbles decreased when the clearance between the lower end of inner tube or division plate and the bottom of column was small.

\subsection{Mean Gas Holdup}

In the case of rectangular internal-loop bubble column (RIL) for example, the mean gas holdup in riser $\varepsilon_{\mathrm{GR}}$ increased in proportion to $U_{\mathrm{GR}}$ in the higher range of $U_{\mathrm{GR}}$ as demonstrated in Figure 2. The same behaviour was observed in the case of external-loop reactor (EL and ELS). The solid line in Figure 2 shows an Akita-Yoshida equation [7] obtained empirically in the loop bubble column with a concentric-tube using a single hole gas sparger. $\varepsilon_{\mathrm{GR}}$ was usually larger than $\varepsilon_{\mathrm{GD}}$ in the observed region of $U_{\mathrm{GR}}$. A relation of $\varepsilon_{\mathrm{GD}}$ to $\varepsilon_{\mathrm{GR}}$ depends generally on $R$ and $H_{\mathrm{C}}$ which is the clearance between the bottom of the column and the lower end of the division plate. In the case of $H_{\mathrm{C}}=0.24 \mathrm{~m}, \varepsilon_{\mathrm{GD}}$ increased in proportion to $\varepsilon_{\mathrm{GR}}$ from a threshold value of $\varepsilon_{\mathrm{GR}}$ as Figure 3, which also suggests that the decrease of $R$ tends to intensify the dependency of $\varepsilon_{\mathrm{GD}}$ to $\varepsilon_{\mathrm{GR}}$. The decrease of crosssectional area of down downcomer was empirically found to encourage the formation of liquid down flow containing bubbles. The bubble entrainments have been also observed in the external-loop type airlift bubble column, resulting in another threshold value of $\varepsilon_{\mathrm{GR}}$. On the other hand, in the case of $H_{\mathrm{C}}=0.015 \mathrm{~m}, \varepsilon_{\mathrm{GD}}$ kept to be approximately zero with increasing $\varepsilon_{\mathrm{GR}}$.

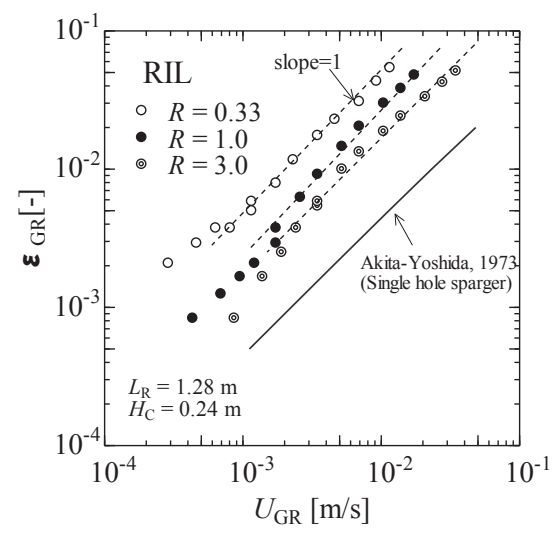

Fig. 2. Changes of $\varepsilon_{\mathrm{GR}}$ with $U_{\mathrm{GR}}$ and $R$ in case of $H_{\mathrm{C}}=0.24 \mathrm{~m}$.

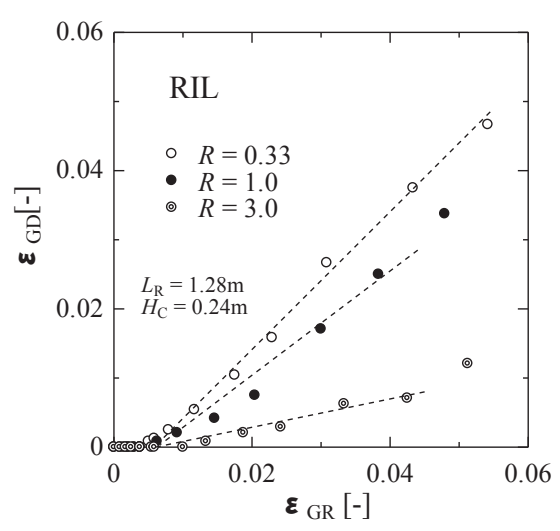

Fig. 3. Relations between $\varepsilon \mathrm{GD}$ and $\varepsilon_{\mathrm{GR}}$ in case of $H_{\mathrm{C}}=0.24 \mathrm{~m}$. 


\subsection{Liquid Circulation Time}

In the internal-loop bubble columns (RIL and CIL), $T_{\mathrm{C}}$ have been found to increase in proportion to the $-1 / 3$ power of $U_{\mathrm{GR}}$ in the lower $U_{\mathrm{GR}}$ region, and $T_{\mathrm{C}}$ was constant with increasing $U_{\mathrm{GR}}$ in the higher $U_{\mathrm{GR}}$ region larger than $3 \times 10^{-3} \mathrm{~m} / \mathrm{s}$. These results stem from the characteristics of liquid flow and entrained bubbles in the column, where bubbles on the riser rise straight without coalescence or entrainment to the downcomer. $T_{\mathrm{C}}$ has been also found to depend on $H_{\mathrm{C}}$ and $R$. When $H_{\mathrm{C}}=0.24 \mathrm{~m}$, the time required to maintain a constant $T_{\mathrm{C}}$ increases with an increase in $R$ as shown in Figure 4 . These belabours of $T_{\mathrm{C}}$ were approximately same in the external-loop type columns. All the data of $T_{\mathrm{C}} U_{\mathrm{GR}}{ }^{1 / 3}$ observed in four types of airlift bubble column, are empirically related to $L_{\mathrm{R}}$ as shown in Figure 5.

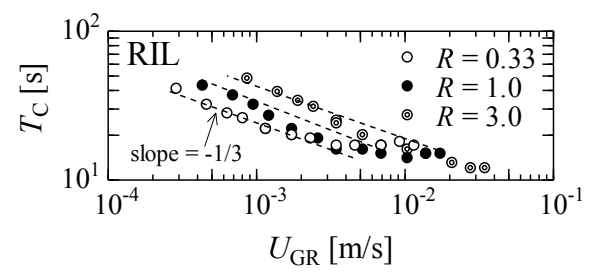

Fig. 4. Dependency of $T_{\mathrm{C}}$ on $U_{\mathrm{GR}}$ and $R$ in case of $H_{\mathrm{C}}=0.24 \mathrm{~m}$.
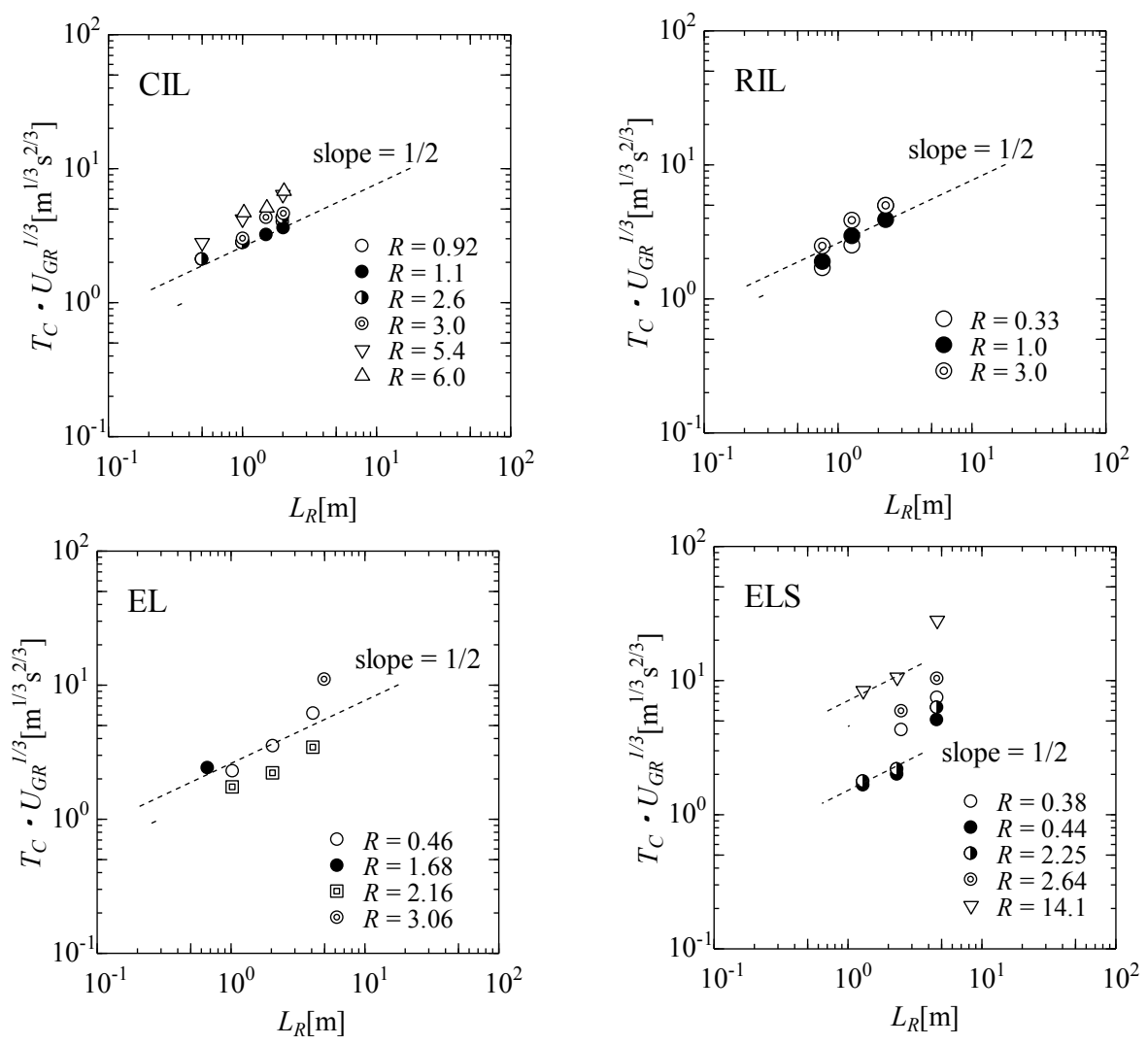

Fig. 5. Relationship between $T_{\mathrm{c}} U_{\mathrm{GR}}{ }^{1 / 2}$ and $L_{\mathrm{R}}$ in the four types of loop airlift bubble column. 
The results indicate that the values of $T_{\mathrm{C}} U_{\mathrm{GR}}{ }^{1 / 3}$ are nearly proportional to the $1 / 2$ power of $L_{\mathrm{R}}$, suggesting that the values of $T_{\mathrm{C}} U_{\mathrm{GR}}{ }^{1 / 3} L_{\mathrm{R}}{ }^{-1 / 2}$ should be constant. Kawasaki et al. [3] have proposed an empirical equation as

$$
T_{\mathrm{C}}=2.5 U_{\mathrm{GR}^{-1 / 3}} L_{\mathrm{R}}^{1 / 2}
$$

which has been derived from the data using the CIL type bubble column in the region $0.7 \leq R \leq 2.5$. Figure 6 demonstrates that the observed results in the present paper are reasonably explained by Equation (1), suggesting that Equation (1) can be applied to various types of loop airlift bubble column.

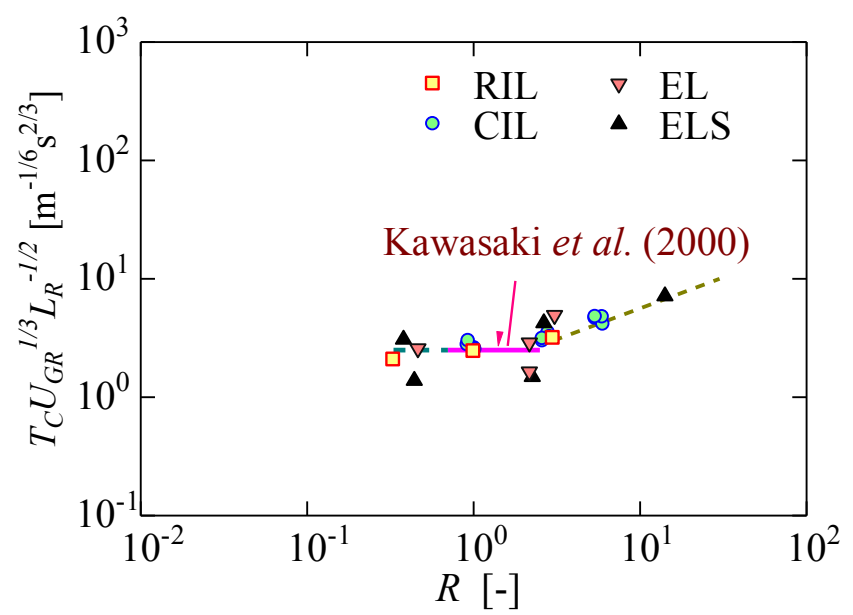

Fig. 6. Relationship between $T_{\mathrm{c}} U_{\mathrm{GR}}{ }^{1 / 3} L_{\mathrm{R}}{ }^{-1 / 2}$ and $R$ obtained for four types of loop airlift bubble column.

\section{Conclusions}

Four types of airlift type bubble column have been employed to observe the effects of the geometric parameters on the bubble distribution patterns. In the experiments the superficial gas velocity in the riser $\left(U_{\mathrm{GR}}\right)$, the gas holdup $\left(\varepsilon_{\mathrm{GR}}, \varepsilon_{\mathrm{GR}}\right)$, the liquid circulation time $\left(T_{\mathrm{C}}\right)$ have been measured and correlated with various geometric parameters. The empirical equation observed in concentric-tube internal-loop airlift type bubble column can be reasonably applied to other three types of loop airlift bubble column.

The authors would like to thank Mr. Takumi Uesugi for his experimental assistance.

\section{References}

1. M.Y. Chisti, M. Moo-Young, Chem. Eng. Comm. 60, 195-242 (1987)

2. M.Y. Chisti, Airlift Bioreactors (Elsevier, 1989)

3. H. Kawasaki, T. Yamamoto, H. Kumazawa, Seibutsu-kogaku Kaishi 78, 115-119 (2000) (in Japanese)

4. L. Meng, Y. Bando, S. Hamano, Y. Oura, M. Nakamura, J. Chem. Eng. Jpn, 38, 1015-1019 (2005) 
5. R.A. Bello, C.W. Robinson, M. Moo-young, Can. J. Chem. Eng. 62, 573-577 (1984)

6. T. Yamamoto, T. Uesugi, H. Kawasaki, Proc. CHISA 2014, P3.199 (Praha, 2014)

7. K. Akita, F. Yoshida, Ind. Eng. Chem. Process Des. Develop. 12, 76-80 (1973) 